\title{
A Pharmacokinetic Study of Ephedrine and Pseudoephedrine after Oral Administration of Ojeok-San by Validated LC-MS/MS Method in Human Plasma
}

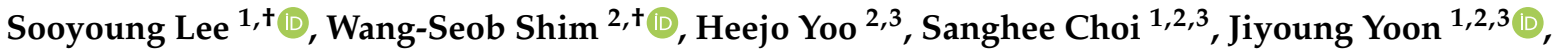 \\ Kwang-Young Lee ${ }^{3}$, Eun-Kyoung Chung ${ }^{4} \mathbb{D}$, Byung-Cheol Lee ${ }^{5} \mathbb{D}$, Sung-Vin Yim ${ }^{6,7} \mathbb{D}$, Bo-Hyung Kim $^{1,6,7,8, * \mathbb{D}}$ \\ and Kyung-Tae Lee ${ }^{1,2,3, * \mathbb{D}}$
}

Citation: Lee, S.; Shim, W.-S.; Yoo, H.; Choi, S.; Yoon, J.; Lee, K.-Y.; Chung, E.-K.; Lee, B.-C.; Yim, S.-V.; Kim, B.-H.; et al. A Pharmacokinetic Study of Ephedrine and Pseudoephedrine after Oral Administration of Ojeok-San by Validated LC-MS/MS Method in Human Plasma. Molecules 2021, 26, 6991. https://doi.org/ $10.3390 /$ molecules26226991

Academic Editor: Míriam Pérez Trujillo

Received: 4 November 2021 Accepted: 18 November 2021 Published: 19 November 2021

Publisher's Note: MDPI stays neutral with regard to jurisdictional claims in published maps and institutional affiliations.

Copyright: (c) 2021 by the authors. Licensee MDPI, Basel, Switzerland. This article is an open access article distributed under the terms and conditions of the Creative Commons Attribution (CC BY) license (https:// creativecommons.org/licenses/by/ $4.0 /)$.
1 Department of Biomedical and Pharmaceutical Sciences, Graduate School, Kyung Hee University, Seoul 02447, Korea; 1s009@khu.ac.kr (S.L.); tkdgml117@gmail.com (S.C.); yoon02j27y@khu.ac.kr (J.Y.)

2 Kyung Hee Drug Analysis Center, College of Pharmacy, Kyung Hee University, Seoul 02447, Korea; wsshimm@khu.ac.kr (W.-S.S.); heejoyoo93@gmail.com (H.Y.)

3 Department of Pharmaceutical Biochemistry, College of Pharmacy, Kyung Hee University, Seoul 02447, Korea; gloryi@naver.com

4 Department of Fundamental Pharmaceutical Science, Graduate School, Kyung Hee University, Seoul 02447, Korea; cekchung@khu.ac.kr

5 Department of Clinical Korean Medicine, Graduate School, Kyung Hee University, Seoul 02447, Korea; hydrolee@khu.ac.kr

6 Department of Clinical Pharmacology and Therapeutics, Kyung Hee University Medical Center, Seoul 02447, Korea; ysvin@khu.ac.kr

7 Department of Biomedical Science and Technology, Graduate School, Kyung Hee University, Seoul 02447, Korea

8 East-West Medical Research Institute, Kyung Hee University, Seoul 02447, Korea

* Correspondence: bhkim98@khu.ac.kr (B.-H.K.); ktlee@khu.ac.kr (K.-T.L.)

$+\quad$ These authors contributed equally to the first authors.

Abstract: A sensitive and reproducible liquid chromatography-tandem mass spectrometry (LCMS/MS) system was developed and fully validated for the simultaneous determination of ephedrine and pseudoephedrine in human plasma after oral administration of the herbal prescription Ojeok-san (OJS); 2-phenylethylamine was used as the internal standard (IS). Both compounds presented a linear calibration curve $\left(r^{2} \geq 0.99\right)$ over a concentration range of $0.2-50 \mathrm{ng} / \mathrm{mL}$. The developed method was fully validated in terms of selectivity, lower limit of quantitation, precision, accuracy, recovery, matrix effect, and stability, according to the regulatory guidelines from the U.S. Food and Drug Administration and the Korea Ministry of Food and Drug Safety. This validated method was successfully applied for the pharmacokinetic assessment of ephedrine and pseudoephedrine in 20 healthy Korean volunteers administered OJS.

Keywords: ephedrine; pseudoephedrine; liquid chromatography-tandem mass spectrometry; bioanalytical method validation; pharmacokinetics; healthy volunteers

\section{Introduction}

As herbal medicines are gaining momentum worldwide [1], the number of patients taking prescribed herbal medicines is simultaneously growing [2]. According to statistical data of the Health Insurance Review and Assessment Service, among 56 herbal prescriptions, Ojeok-san (OJS; wuji-power in China and goshakusan in Japan) was the most commonly prescribed herbal medicine in 2013. OJS is composed of 15 medicinal herbs: Atractylodes lancea D.C., Ephedra sinica Stapf, Citrus unshiu Markovich, Magnolia officinalis Rehd. et Wils., Platycodon grandiflorum A. DC., Angelica gigas Nakai, Zingiber officinale Rosc., Paeonia lactiflora Pall., Poria cocos Wolf, Cnidium officinale Makino, Angelica dahurica Benth. et Hook. f., Pinellia ternata Breit., Cinnamomum cassia Presl, Glycyrrhiza uralensis Fisch., and Allium 
fistulosum L. In Asian countries, including Korea, China, and Japan, OJS has long been used for treating common colds and illnesses, including gastrointestinal disorders. To date, various studies have reported the analgesic, anti-inflammatory, anti-allergic, and anti-oxidative properties of OJS [3-6].

It should be noted that, in contrast with synthetic chemical drugs, a single herbal medicine prescription can contain hundreds of active ingredients. Among these ingredients, Ehpedrae Herba, called Ma Huang in China, acts as a diaphoretic to alleviate fever [7]. The chemical components of Ma Huang have been separated and established for approximately 100 years, and the main components include ephedrine alkaloids, such as ephedrine, pseudoephedrine, and methylephedrine. The effect of Ma Huang is mainly attributed to sympathetic stimulation mediated by ephedrine and pseudoephedrine, which increases the activity of $\alpha$ - and $\beta$-adrenergic receptors [8]. However, ephedrine interacts with caffeine, amphetamine, nose decongestants, and several other drugs [9-11]. In addition, the concentration of ephedrine in rat plasma was found to differ from that following a single ephedrine extract and multi-herbal decoction [12]. Therefore, comprehensively elucidating the pharmacokinetic patterns of ephedrine and pseudoephedrine in human plasma after oral administration of OJS is vital to ensure its safe use.

Methods for estimating ephedrine and pseudoephedrine using high-pressure liquid chromatography (HPLC) with fluorescence detection after derivatization [13] or capillary electrophoresis have been previously reported [14,15]. However, these methods have some limitations, given the complicated sample processing procedure and low sensitivity. In addition, previous studies have described liquid chromatography with tandem mass spectrometry detection (LC-MS/MS), which was reportedly simpler and more sensitive for analyzing six ephedra alkaloids in dietary supplements and biological fluids [16], as well as ephedrine and pseudoephedrine in rat plasma and horse urine [17-19]. LC-MS/MS was employed for determining nine herbal phenalkylamines in human plasma, including ephedrine and pseudoephedrine [20]. However, this method was developed with a $10 \mathrm{ng} / \mathrm{mL}$ detection limit and was not applied for pharmacokinetic investigations. To our knowledge, no sensitive and reproducible LC-MS/MS method for simultaneous analytical method has been developed for ephedrine and pseudoephedrine in human plasma samples. Furthermore, the development of new and simultaneous ephedrine and pseudoephedrine analytical method was imperative for high-throughput and reliable sample analysis to conduct large-scale pharmacokinetic studies and to routinely measure plasma ephedrine and pseudoephedrine concentrations in the patient. Therefore, the objective of the present study was to develop a fully validated LC-MS/MS method for the simultaneous determination of two main active components, ephedrine and pseudoephedrine, in human plasma. The developed method was then applied to evaluating 20 healthy Korean male volunteers administered OJS powder.

\section{Results and Discussion}

\subsection{Method Development}

\subsubsection{Mass Spectrometry}

Ephedrine, pseudoephedrine, and IS, at a concentration of $100 \mathrm{ng} / \mathrm{mL}$ in methanol, were individually infused into the mass spectrometer using a syringe pump at a continuous flow rate of $10 \mu \mathrm{L} / \mathrm{min}$ to optimize the mass spectrometric conditions and achieve the maximum abundance of product and fragment ions in a positive ionization mode using a Turboionspray ESI interface. Q1 full-scan spectra were characterized by protonated molecules $[\mathrm{M}+\mathrm{H}]^{+}$at $m / z 166.2$ for ephedrine and pseudoephedrine and $m / z 121.98$ for IS. The selected product ions were $m / z 148.2$ for both ephedrine and pseudoephedrine; $m / z 105.0$ was selected for the IS (Figure 1). 


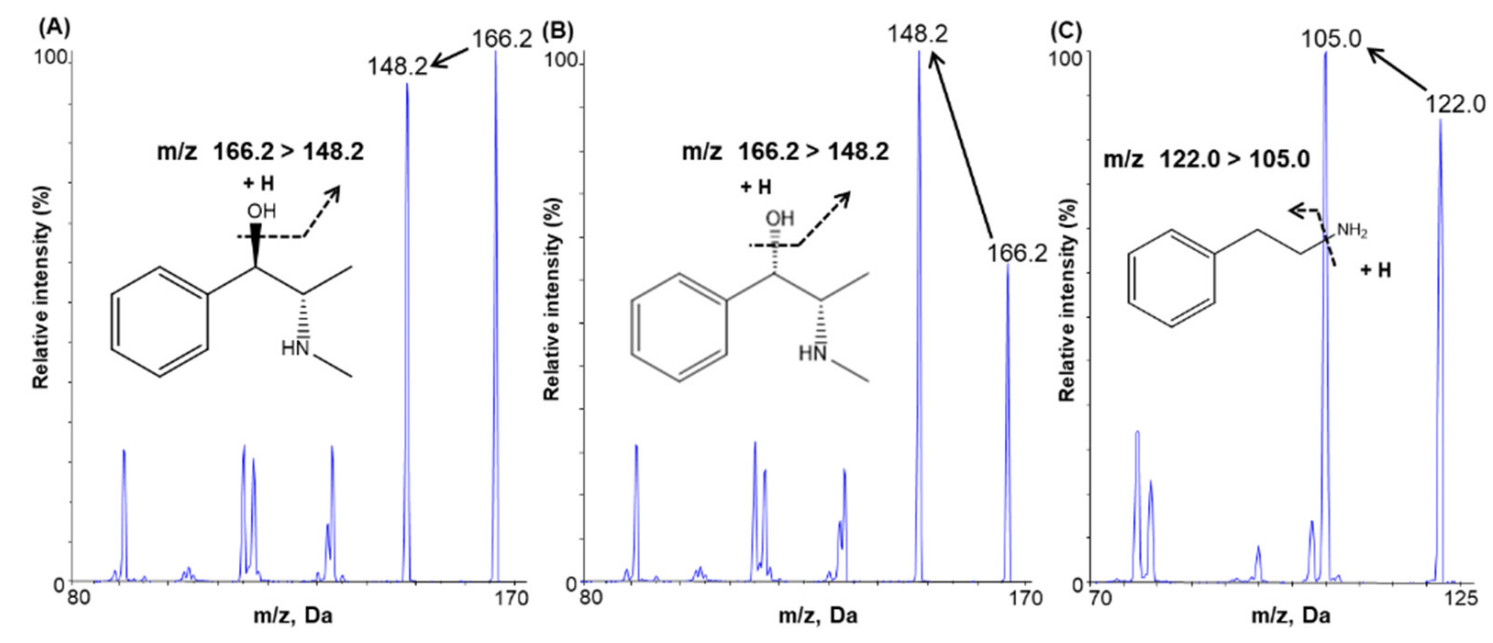

Figure 1. Product ion mass spectra and the pattern of fragmentation of (A) ephedrine, (B) pseudoephedrine, and (C) 2phenylethylamine (internal standard).

\subsubsection{Chromatographic Conditions}

Chromatographic conditions, including the column, column temperature, mobile phase composition, and flow rate, were optimized to achieve an adequate peak shape, separation, and run time. In the present study, the following chromatographic columns were evaluated for optimal separation results: Imtakt Cadenza ${ }^{\circledR}$ CD-C18 column $(150 \times 3.0 \mathrm{~mm}$, $3 \mu \mathrm{m})$, Phenomenex Kinetex ${ }^{\circledR} \mathrm{C} 18$ column $(150 \times 4.6 \mathrm{~mm}, 2.6 \mu \mathrm{m})$, DAICEL CHIRALPAK ${ }^{\circledR}$ AGP $(150 \times 2.0 \mathrm{~mm}, 5 \mu \mathrm{m})$, and Halo ${ }^{\circledR}$ Phenyl-Hexyl column $(150 \times 2.1 \mathrm{~mm}, 2.7 \mu \mathrm{m})$. Accordingly, the Halo ${ }^{\circledR}$ Phenyl-Hexyl column presented the best results in terms of peak shape, separation, and chromatographic response. The remaining tested columns exhibited poor peak separation. In addition, mobile phases containing different additives, such as formic acid, acetic acid, and ammonium acetate, were evaluated using the gradient method to optimize the peak intensity and chromatographic separation of the two analytes. The most adequate peak shape and selectivity were obtained using $20 \mathrm{mM}$ ammonium acetate adjusted to $\mathrm{pH} 5$ by adding acetic acid to solvent $\mathrm{A}$ and methanol for solvent $\mathrm{B}$. Ultimately, the Halo ${ }^{\circledR}$ Phenyl-Hexyl column $(150 \times 2.1 \mathrm{~mm}, 2.7 \mu \mathrm{m})$ and mobile phase composed of $20 \mathrm{mM}$ ammonium acetate adjusted to $\mathrm{pH} 5$ by adding acetic acid and methanol with gradient elution afforded good separation of the two analytes, exhibiting optimal sensitivity, good resolution, and adequate peak shape, thus satisfying the requirements of sample analysis for pharmacokinetic investigations.

\subsubsection{Sample Preparation}

According to previous reports [21,22], the liquid-liquid extraction (LLE) method was initially evaluated using MTBE as the extraction solvent. However, given the insufficient recovery, different extraction solvents were evaluated, including methylene chloride, ethyl acetate, $n$-hexane, mixtures of MTBE:methylene chloride $(8: 2 ; v / v)$, and mixtures of ethyl acetate: $n$-hexane $(8: 2 ; v / v)$. In addition, sample buffers such as formic acid, hydrochloric acid, and sodium hydroxide, and reconstitution solvents, including methanol and acetonitrile, were assessed to optimize the analyte peak intensity. Ultimately, the highest peak intensity and high analyte recovery were obtained using $3 \mathrm{~mL}$ MTBE:methylene chloride $(8: 2 ; v / v)$ and $20 \mu \mathrm{L}$ sodium hydroxide $(10 \mathrm{mM})$ as an extraction buffer. Therefore, to meet the requirements for analyzing our 360 plasma samples, we selected one-step LLE using MTBE:methylene chloride $(8: 2 ; v / v)$ as the extraction solvent.

\subsection{Method Validation}

\subsubsection{Specificity and Selectivity}

We employed six different blank plasmas and pooled blank plasmas to verify selectivity at each step. The chromatograms of blank plasma, blank plasma spiked with 
IS $(5 \mu \mathrm{g} / \mathrm{mL})$, blank plasma spiked with ephedrine $(0.2 \mathrm{ng} / \mathrm{mL})$, blank plasma spiked with pseudoephedrine $(0.2 \mathrm{ng} / \mathrm{mL})$, blank plasma spiked with ephedrine $(0.2 \mathrm{ng} / \mathrm{mL})$, pseudoephedrine, $(0.2 \mathrm{ng} / \mathrm{mL})$, and IS $(5 \mu \mathrm{g} / \mathrm{mL})$ showed no interfering peaks at analyte and IS retention times, thus indicating the adequate selectivity of the newly developed analytical method (Figure 2).

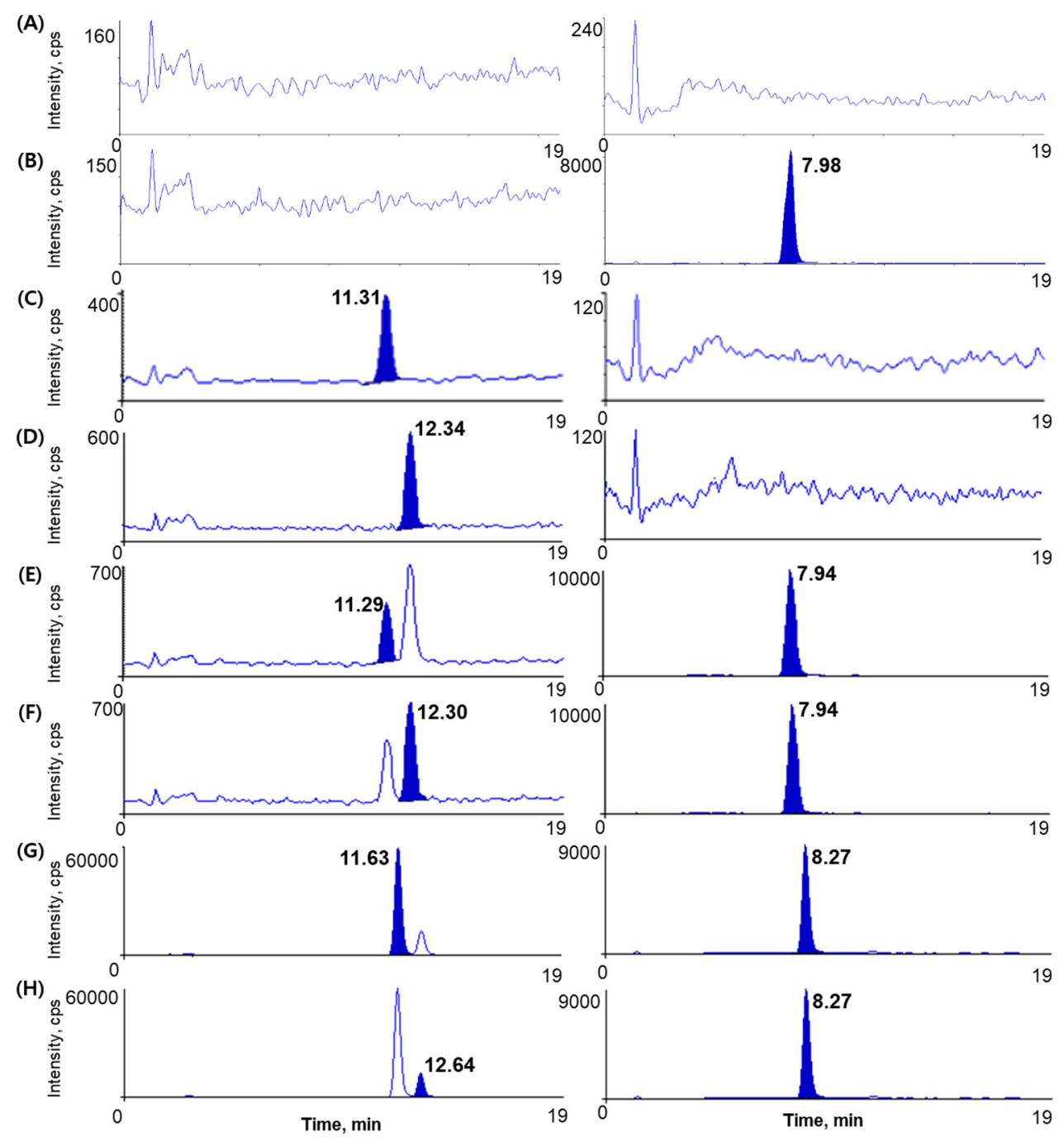

Figure 2. Chromatograms of (A) Blank human plasma, (B) Blank plasma spiked with IS (5 $\mu \mathrm{g} / \mathrm{mL}$ ), (C) Blank plasma spiked with ephedrine only $(0.2 \mathrm{ng} / \mathrm{mL}$, LLOQ), (D) Blank plasma spiked with pseudoephedrine only $(0.2 \mathrm{ng} / \mathrm{mL}$, LLOQ), (E) Blank plasma spiked with ephedrine $(0.2 \mathrm{ng} / \mathrm{mL})$ and IS (5 $\mu \mathrm{g} / \mathrm{mL})$, (F) Blank plasma spiked with pseudoephedrine $(0.2 \mathrm{ng} / \mathrm{mL}$ and IS $(5 \mu \mathrm{g} / \mathrm{mL})$, (G) Ephedrine (measured concentration $27.23 \mathrm{ng} / \mathrm{mL}$ ) in sample plasma from a patient $1 \mathrm{~h}$ after administering an oral dose of $14.47 \mathrm{~g}$ OJS powder and IS $(5 \mu \mathrm{g} / \mathrm{mL})$, and $(\mathbf{H})$ Pseudoephedrine (measured concentration $4.08 \mathrm{ng} / \mathrm{mL}$ ) of sample plasma from a patient at $1 \mathrm{~h}$ after administering an oral dose of $14.47 \mathrm{~g}$ OJS powder and IS $(5 \mu \mathrm{g} / \mathrm{mL})$.

\subsubsection{Linearity and Lower Limit of Quantification}

Using linear regression, calibration curves for ephedrine and pseudoephedrine were plotted with seven concentrations, ranging over $0.2-50 \mathrm{ng} / \mathrm{mL}$. The equation for the calibration curves $(n=4)$ with the mean \pm SD of the slope and the intercept was: $y=0.251( \pm 0.014)$ $x+0.007( \pm 0.009)\left(r^{2} \geq 0.9906\right)$, and $y=0.412( \pm 0.012) x+0.014( \pm 0.009)\left(r^{2} \geq 0.9902\right)$ for ephedrine and pseudoephedrine, respectively. The correlation coefficients were greater than 0.99 for all curves, and between-run CVs of response factors were $<15 \%$ over the assayed concentration range. The signal-to-noise ratio (S/N ratio) of the LLOQ $(0.2 \mathrm{ng} / \mathrm{mL})$ 
suggests a sufficiently sensitive method to quantitate ephedrine and pseudoephedrine in plasma following the oral administration of OJS to human volunteers.

\subsubsection{Precision and Accuracy}

Table 1 summarizes the intra- and inter-day assay precision and accuracy for ephedrine and pseudoephedrine. The intra-day precision of the method to determine ephedrine and pseudoephedrine concentrations ranged from $5.88 \%$ to $14.99 \%$ and $8.33 \%$ to $10.92 \%$, with an accuracy ranging from $97.10 \%$ to $106.40 \%$ and $86.78 \%$ to $103.70 \%$, respectively. The inter-day precision ranged from $10.97 \%$ to $12.53 \%$ and from $8.77 \%$ to $13.74 \%$, with an accuracy ranging from $91.56 \%$ to $94.07 \%$ and $89.88 \%$ to $93.00 \%$, respectively, for estimating ephedrine and pseudoephedrine concentrations. Thus, all results satisfied the precision and accuracy ranges (\%), as specified in the guidance of the MFDS and the FDA for bioanalytical applications $[23,24]$.

Table 1. Intra- and inter-day precision and accuracy of ephedrine and pseudoephedrine $(n=5)$.

\begin{tabular}{|c|c|c|c|c|c|c|c|c|c|c|c|}
\hline \multirow[b]{2}{*}{ Compound } & \multirow{2}{*}{$\begin{array}{c}\text { Nominal } \\
\text { Concentration } \\
(\mathrm{ng} / \mathrm{mL})\end{array}$} & \multicolumn{5}{|c|}{ Intra-Day $(n=5)$} & \multicolumn{5}{|c|}{ Inter-Day $(n=5)$} \\
\hline & & \multicolumn{3}{|c|}{$\begin{array}{c}\text { Mean } \pm \text { SD } \\
(\mathrm{ng} / \mathrm{mL})\end{array}$} & \multirow{2}{*}{$\begin{array}{c}\begin{array}{c}\text { Precision } \\
(\mathrm{CV}, \mathbf{\%})^{\mathrm{a}}\end{array} \\
14.99\end{array}$} & \multirow{2}{*}{$\begin{array}{c}\begin{array}{c}\text { Accuracy } \\
(\%)^{b}\end{array} \\
97.10\end{array}$} & \multicolumn{3}{|c|}{$\begin{array}{c}\text { Mean } \pm \text { SD } \\
(\mathrm{ng} / \mathrm{mL})\end{array}$} & \multirow{2}{*}{$\begin{array}{c}\begin{array}{c}\text { Precision } \\
\text { (CV, \%) }\end{array} \\
11.38\end{array}$} & \multirow{2}{*}{$\begin{array}{c}\begin{array}{c}\text { Accuracy } \\
(\%)\end{array} \\
94.07\end{array}$} \\
\hline \multirow{4}{*}{ Ephedrine } & 0.2 & 0.19 & \pm & 0.03 & & & 0.19 & \pm & 0.02 & & \\
\hline & 0.6 & 0.60 & \pm & 0.05 & 8.85 & 100.57 & 0.55 & \pm & 0.06 & 11.09 & 91.56 \\
\hline & 10 & 10.26 & \pm & 0.63 & 6.09 & 102.62 & 9.21 & \pm & 1.01 & 10.97 & 92.09 \\
\hline & 50 & 53.20 & \pm & 3.13 & 5.88 & 106.40 & 46.20 & \pm & 5.79 & 12.53 & 92.40 \\
\hline \multirow{4}{*}{$\begin{array}{l}\text { Pseudo- } \\
\text { ephedrine }\end{array}$} & 0.2 & 0.21 & \pm & 0.02 & 9.32 & 103.70 & 0.19 & \pm & 0.03 & 13.74 & 93.00 \\
\hline & 0.6 & 0.55 & \pm & 0.06 & 10.92 & 90.80 & 0.54 & \pm & 0.05 & 8.77 & 89.88 \\
\hline & 10 & 8.68 & \pm & 0.72 & 8.33 & 86.78 & 9.15 & \pm & 0.83 & 9.02 & 91.53 \\
\hline & 50 & 43.47 & \pm & 3.68 & 8.45 & 86.95 & 45.39 & \pm & 4.47 & 9.84 & 90.78 \\
\hline
\end{tabular}

${ }^{\mathrm{a}} \mathrm{CV}(\%)=($ standard deviation of calculated concentrations/mean concentration $) \times 100 . \quad \mathrm{b}$ Accuracy $(\%)=($ predicted concentration/nominal concentration) $\times 100$.

\subsubsection{Recovery and Matrix Effect}

The extraction recovery and matrix effects are summarized in Table 2. Following LLE, the mean extraction recoveries from human plasma at three QC concentrations $(0.6,10$, and $40 \mathrm{ng} / \mathrm{mL}, n=6$ ) were $73.31-76.09 \%$ for ephedrine and $71.44-72.97 \%$ for pseudoephedrine were. The mean extraction recovery of the IS $(5 \mu \mathrm{g} / \mathrm{mL}, n=6)$ was $67.76 \%$. The mean matrix effects for ephedrine at QC concentrations $(0.6,10$, and $40 \mathrm{ng} / \mathrm{mL}, n=6)$ were $100.48-102.15 \%$, and matrix effects for pseudoephedrine were $101.60-105.17 \%$. These were well within the acceptable limits, suggesting the absence of significant ion enhancement or suppression effects on ephedrine and pseudoephedrine.

Table 2. Extraction recovery and matrix effect of ephedrine, pseudoephedrine, and IS.

\begin{tabular}{|c|c|c|c|c|c|c|c|c|c|}
\hline \multirow{2}{*}{ Compound } & \multirow{2}{*}{$\begin{array}{l}\text { Nominal Concentration } \\
(\mathrm{ng} / \mathrm{mL})\end{array}$} & \multicolumn{4}{|c|}{ Recovery $(\%)^{a}$} & \multicolumn{4}{|c|}{ Matrix Effect (\%) } \\
\hline & & \multicolumn{3}{|c|}{ Mean \pm SD (\%) } & \multirow{2}{*}{$\frac{\mathrm{CV}(\%)}{6.53}$} & \multicolumn{3}{|c|}{ Mean \pm SD (\%) } & \multirow{2}{*}{$\frac{\mathrm{CV}(\%)}{3.82}$} \\
\hline \multirow{3}{*}{ Ephedrine } & 0.6 & 76.09 & \pm & 4.97 & & 100.48 & \pm & 3.84 & \\
\hline & 10 & 76.04 & \pm & 2.17 & 2.86 & 101.99 & \pm & 2.87 & 2.82 \\
\hline & 40 & 73.31 & \pm & 4.14 & 5.65 & 102.15 & \pm & 2.03 & 1.98 \\
\hline \multirow{3}{*}{$\begin{array}{l}\text { Pseudo- } \\
\text { ephedrine }\end{array}$} & 0.6 & 72.76 & \pm & 4.14 & 5.69 & 105.17 & \pm & 2.98 & 2.83 \\
\hline & 10 & 72.97 & \pm & 2.43 & 3.34 & 101.60 & \pm & 1.33 & 1.31 \\
\hline & 40 & 71.44 & \pm & 3.19 & 4.47 & 102.56 & \pm & 1.83 & 1.79 \\
\hline IS & 5000 & 67.76 & \pm & 10.13 & 14.95 & 103.70 & \pm & 10.91 & 10.52 \\
\hline
\end{tabular}

${ }^{\mathrm{a}}$ Extraction recovery $(\%)=[($ peak area of analyte spiked before extraction $) /($ peak area of analyte spiked after extraction $)] \times 100 .{ }^{\mathrm{b}}$ Matrix effect $(\%)=[($ peak area of analyte spiked after extraction $) /($ peak area of analyte in the pure standard solution $)] \times 100$. Data are presented as mean $\pm \operatorname{SD}(n=6)$. 


\subsubsection{Stability}

Compared with a freshly prepared stock solution of ephedrine and pseudoephedrine, the mean \% peak area of the working solution of ephedrine and pseudoephedrine at room temperature for $7 \mathrm{~h}$ was $96.26 \%$ and $96.98 \%$ and $99.12 \%$ and $96.93 \%$ at 0.6 and $40 \mathrm{ng} / \mathrm{mL}$, respectively. As shown in Table 3, both ephedrine and pseudoephedrine were stable in plasma for up to $7 \mathrm{~h}$ at room temperature, $4{ }^{\circ} \mathrm{C}$, and $-70{ }^{\circ} \mathrm{C}$. In addition, the freezethaw stabilities of analytes were adequate $(85.83-99.50 \%)$ after five freeze-thaw cycles. In addition, the samples were stable $(87.22-109.60 \%)$ in the autosampler $\left(10^{\circ} \mathrm{C}\right)$ for $97 \mathrm{~h}$ after LLE. Therefore, based on observed deviations from the nominal concentration within \pm $15 \%$, ephedrine and pseudoephedrine were considered stable in human plasma under all examined conditions without substantial degradation.

Table 3. Stability data for ephedrine and pseudoephedrine in human plasma samples $(n=3)$.

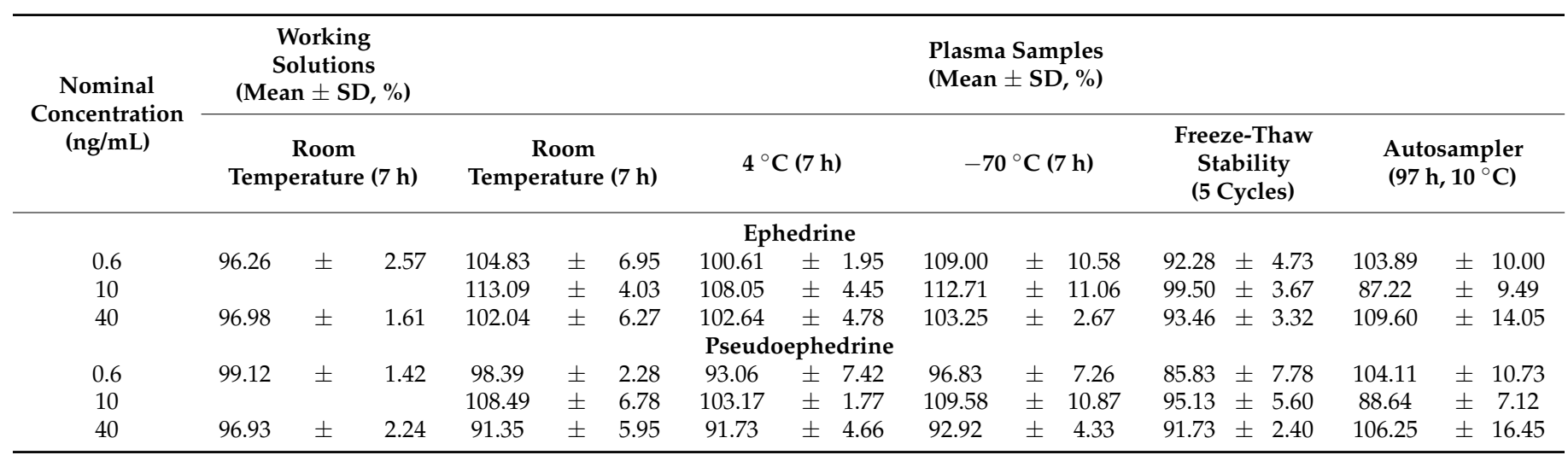

\subsection{Application to a Pharmacokinetic Study}

The developed and validated analytical method was successfully used to analyze approximately 360 human plasma samples to estimate the pharmacokinetic interaction of OJS in 20 healthy Korean volunteers. The study findings have been previously reported, except for the pharmacokinetics of ephedrine and pseudoephedrine [25]. However, at the time of publication, the concentrations of ephedrine and pseudoephedrine could not be determined simultaneously. Therefore, additional developments were required to overcome analytical difficulties associated with simultaneous quantification.

Figure 3 shows the mean $\pm \mathrm{SD}$ (or individual) plasma concentration-time curve of ephedrine and pseudoephedrine in the plasma samples of 20 healthy volunteers after oral administration of OJS powder. The pharmacokinetic parameters of ephedrine and pseudoephedrine are listed in Table 4. We thought that steady-state was already reached on day 5 after the first OJS dose, given the five half-lives of each compound. Therefore, for calculating pharmacokinetic parameters, the concentrations of blood samples on days 5 and 7 were used as $0 \mathrm{~h}$ pre-OJS dosing and $0.5 \mathrm{~h}$ post-OJS dosing concentrations, respectively.

The concentrations of ephedrine from 8 subjects and pseudoephedrine from all subjects were below the LLOQ at $49 \mathrm{~h}$ after the last OJS dose. In contrast, all concentrations of both components were detectable at $25 \mathrm{~h}$. Thus, $25 \mathrm{~h}$ was used as the last concentration time to calculate the $\mathrm{AUC}_{\text {last }}$. Additionally, the mean $\pm \mathrm{SD}$ of $\mathrm{AUC}_{\text {last }}$ of ephedrine, including $49 \mathrm{~h}$, was $353.78 \pm 101.42$; this value did not considerably differ from the $\mathrm{AUC}_{\text {last }}$ of ephedrine, excluding $49 \mathrm{~h}(336.88 \mathrm{ng} \cdot \mathrm{h} / \mathrm{mL})$. 


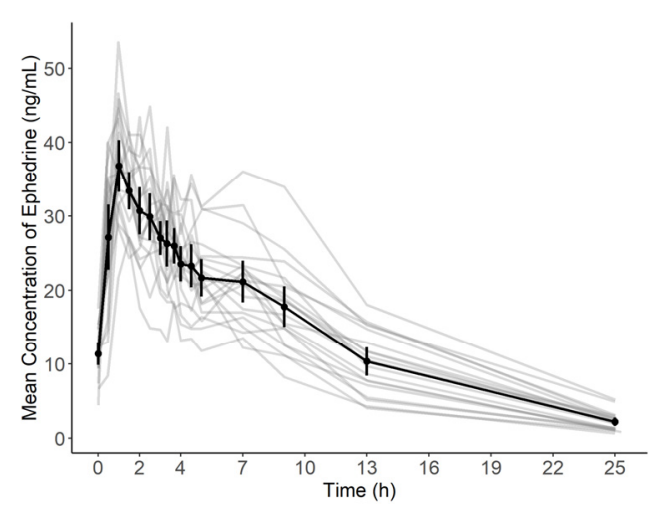

(A)

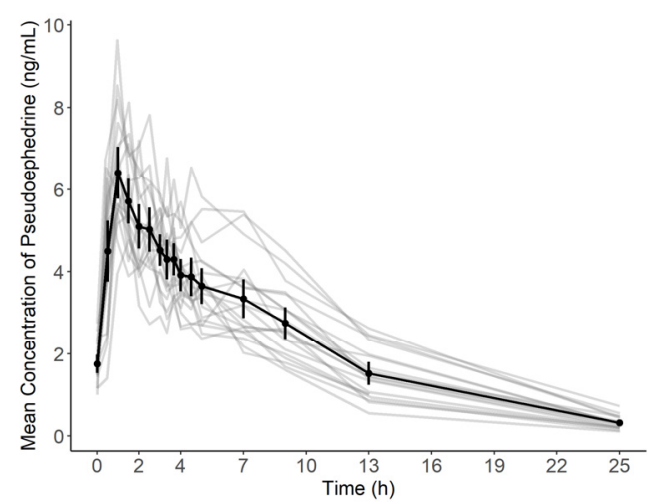

(B)

Figure 3. Mean ( \pm standard deviation) plasma concentration-time profile of ephedrine and pseudoephedrine in the plasma samples of 20 healthy volunteers after the oral administration of OJS powder overlaid on gray individual spaghetti plots: (A) Ephedrine; (B) Pseudoephedrine.

Table 4. Pharmacokinetic parameter estimates of ephedrine and pseudoephedrine after the oral administration of OJS powder. $(n=20)$.

\begin{tabular}{ccccccc}
\hline Parameter & \multicolumn{3}{c}{$\begin{array}{c}\text { Ephedrine } \\
\text { (Mean } \pm \text { SD) }\end{array}$} & \multicolumn{3}{c}{$\begin{array}{c}\text { Pseudoephedrine } \\
\text { (Mean } \pm \text { SD) }\end{array}$} \\
\hline $\mathrm{C}_{\max , \mathrm{ss}}(\mathrm{ng} / \mathrm{mL})$ & 39.24 & \pm & 6.45 & 6.83 & \pm & 1.19 \\
$\mathrm{AUC}_{\text {last }}(\mathrm{ng} \cdot \mathrm{h} / \mathrm{mL})$ & 336.88 & \pm & 86.13 & 52.92 & \pm & 13.48 \\
$\mathrm{AUC}_{\tau, \mathrm{ss}}(\mathrm{ng} \cdot \mathrm{h} / \mathrm{mL})$ & 180.49 & \pm & 31.59 & 30.08 & \pm & 5.33 \\
$\mathrm{~T}_{\max }(\mathrm{h})$ & 1.36 & \pm & 1.21 & 1.44 & \pm & 0.85 \\
$\mathrm{t}_{1 / 2}(\mathrm{~h})$ & 5.98 & \pm & 1.23 & 5.20 & \pm & 0.65 \\
\hline
\end{tabular}

$\mathrm{C}_{\text {max,ss, }}$ peak plasma concentration at steady-state; $\mathrm{AUC}_{\text {last }}$, area under the plasma drug concentration-time curve to the last measurable time; $\mathrm{AUC}_{\tau, \mathrm{ss}}$, area under the plasma drug concentration-time curve during dosing interval at steady-state; $\mathrm{T}_{\max }$, time to reach the peak plasma concentration; $\mathrm{t}_{1 / 2}$, terminal half-life.

Previously, the mean \pm SD of half-life of ephedrine were $5.7 \pm 2.2 \mathrm{~h}$ in a pharmacokinetics study assessing 12 healthy volunteers who administered $20 \mathrm{mg}$ ephedrine tablet [26]. In another pharmacokinetics study for 16 volunteers who administered $120 \mathrm{mg}$ pseudoephedrine capsule, the mean \pm SD of half-life of pseudoephedrine were $5.9 \pm 2.2 \mathrm{~h}$ [27] The studies of traditional medicine containing ephedrine and pseudoephedrine were also similar to those reported in this study. In a study assessing six healthy volunteers who administered $0.6 \mathrm{~g}$ Ma Huang preparation, the mean \pm SD of half-lives of ephedrine and pseudoephedrine were $5.6 \pm 1.2$ and $4.9 \pm 0.9 \mathrm{~h}$, respectively [28]. Another study examining 12 healthy volunteers who administered Ma Huang tang $350 \mathrm{~mL}$ (contained Ma Huang $18 \mathrm{~g}$ ) has reported mean $\pm \mathrm{SD}$ of half-lives of $4.2 \pm 1.0 \mathrm{~h}$ and $4.3 \pm 0.8 \mathrm{~h}$ for ephedrine and pseudoephedrine, respectively [29]. No report has addressed the pharmacokinetics of ephedrine and pseudoephedrine in OJS-dosed humans, especially on reaching steady-state. Therefore, this study may be valuable for clarifying the pharmacokinetic characteristics of ephedrine and pseudoephedrine in OJS. In addition, our study found that the half-lives of ephedrine and pseudoephedrine in the current study were similar to those reported in previous studies regardless of drug formulation.

In addition, further studies are needed to analyze ephedrine and pseudoephedrine together with their metabolites, norephedrine and norpseudoephedrine, respectively, in human plasma after OJS administration, although these metabolites are only small amounts [30-33]. These data will give valuable information on the comparative ephedrine and pseudoephedrine metabolism after pure or herbal formulation administration. In this study, there is a limitation for completely determining metabolite pharmacokinetics after OJS administration. Therefore, further analysis and pharmacokinetic studies, including norephedrine and norpseudoephedrine analysis, can help to better understand the metabolic properties of OJS and to use it safely. 


\section{Materials and Methods}

\subsection{Chemicals and Reagents}

Ephedrine (purity 99.7\%) and pseudoephedrine (purity 99.9\%) were obtained from the Ministry of Food and Drug Safety in Korea (MFDS). 2-phenylethylamine (internal standard [IS], purity 100\%), methyl tert-butyl ether (MTBE), and methylene chloride were purchased from Sigma-Aldrich (St. Louis, MO, USA). High-performance liquid chromatography (HPLC)grade acetonitrile and methanol were purchased from J.T. Baker (Phillipsburg, NJ, USA). A Milli- ${ }^{\circledR}$ water purification system (Millipore Co., MA, USA) was used to obtain purified water for HPLC analysis. All other chemicals and solvents used were of the highest available analytical grade. OJS was provided by Hanpoong Pharmaceutical and Food Co. Ltd. (Wanju, Korea). The content of ephedrine, pseudoephedrine, hesperidin, paeoniflorin, cinnamic acid, and glycyrrhizic acid was $1.2,0.16,5.7,3.4,64.8$, and $1.2 \mathrm{mg} / \mathrm{g}$ crude material, respectively.

\subsection{Instrumentation and Chromatographic Conditions}

Liquid chromatography was performed on a Shimadzu Nexera X2 (Shimadzu, Kyoto, Japan), and chromatographic separation was carried out using a Halo ${ }^{\circledR}$ Phenyl-Hexyl column $(150 \times 2.1 \mathrm{~mm}, 2.7 \mu \mathrm{m}$; Advanced Materials Technology, Wilmington, DE, USA). The mobile phase consisted of $20 \mathrm{mM}$ ammonium acetate (pH 5.0, adjusted with acetic acid) and $100 \%$ methanol with a gradient method. The gradient program was as follow: $3 \% \mathrm{~B}$ at $0-2 \mathrm{~min}, 3-13 \% \mathrm{~B}$ at $2-14 \mathrm{~min}, 13 \%$ B at $14-17 \mathrm{~min}, 13-3 \% \mathrm{~B}$ at $17-17.5 \mathrm{~min}, 3 \%$ $B$ at $17.5-19 \mathrm{~min}$. The flow rate was set at $250 \mu \mathrm{L} / \mathrm{min}$. Mass spectrometry detection was performed on an API 4000 triple-quadrupole mass spectrometer (Applied Biosystems SCIEX, Framingham, MA, USA) equipped with an electrospray ion source. Figure 1 shows the MS/MS spectra of ephedrine, pseudoephedrine, and IS with their fragmentation patterns. The optimized source parameters of ephedrine, pseudoephedrine, and IS are listed in Table 5. The analytical data were processed using Analyst ${ }^{\circledR}$ 1.6.2. software (AB SCIEX, Concord, ON, Canada).

Table 5. Optimized MRM parameters and retention time for the determination of ephedrine, pseudoephedrine, and the IS.

\begin{tabular}{ccccccc}
\hline Compound & $\begin{array}{c}\text { Ion Transition } \\
(\boldsymbol{m} / \boldsymbol{z})\end{array}$ & $\begin{array}{c}\text { DP } \\
(\mathbf{V})\end{array}$ & $\begin{array}{c}\text { EP } \\
(\mathbf{V})\end{array}$ & $\begin{array}{c}\text { CE } \\
(\mathbf{V})\end{array}$ & $\begin{array}{c}\text { CXP } \\
(\mathbf{V})\end{array}$ & $\begin{array}{c}\text { RT } \\
(\mathbf{M i n})\end{array}$ \\
\hline $\begin{array}{c}\text { Ephedrine } \\
\text { Pseudoephedrine }\end{array}$ & $166.20 \rightarrow 148.20$ & 40.0 & 6.0 & 15.0 & 8.0 & 11.5 \\
IS (2-phenylethylamine) & $166.20 \rightarrow 148.20$ & 40.0 & 6.0 & 15.0 & 8.0 & 12.5 \\
\hline
\end{tabular}

$\mathrm{DP}$, declustering potential; EP, entrance potential; $\mathrm{CE}$, collision energy; $\mathrm{CXP}$, cell exit potential; RT, retention time.

\subsection{Preparation of Calibration Standards and Quality Control Samples}

Primary stock solutions of ephedrine and pseudoephedrine were prepared at a concentration of $1 \mathrm{mg} / \mathrm{mL}$ in dimethyl sulfoxide (DMSO) and IS was dissolved in deionized water at the same concentration. They were further diluted with $50 \%$ methanol $(v / v)$ to obtain working solutions at several concentrations and stored at $-20{ }^{\circ} \mathrm{C}$. Calibration samples were prepared by spiking ephedrine and pseudoephedrine in blank plasma to obtain the following concentrations: $0.2,0.5,2,5,10,25$, and $50 \mathrm{ng} / \mathrm{mL}$. Quality control (QC) samples were prepared in the same manner as the calibration standards to achieve low, medium, and high concentrations of $0.6,10$, and $40 \mathrm{ng} / \mathrm{mL}$. Calibration and QC samples were freshly prepared on each day of analysis.

\subsection{Plasma Sample Preparation}

Plasma samples were stored in a freezer at $-70{ }^{\circ} \mathrm{C}$ and thawed at room temperature before processing. An aliquot of each plasma sample $(200 \mu \mathrm{L})$ was placed in a borosilicate glass disposable culture tube. IS ( $20 \mu \mathrm{L}, 5 \mu \mathrm{g} / \mathrm{mL}$ of 2-phenylethylamine), $10 \mathrm{mM}$ 
sodium hydroxide $(20 \mu \mathrm{L})$, and MTBE:methylene chloride $=8: 2(v / v)(3 \mathrm{~mL})$ were added, followed by vortexing for $10 \mathrm{~min}$. After centrifugation at $3081 \times \mathrm{g}$ for $10 \mathrm{~min}, 2.7 \mathrm{~mL}$ of the supernatant was transferred to a clean glass culture tube and evaporated to dryness under $\mathrm{N}_{2}$ gas at $50{ }^{\circ} \mathrm{C}$. The residues were reconstituted with $200 \mu \mathrm{L}$ of $50 \%$ methanol $(v / v)$, and $15 \mu \mathrm{L}$ was injected into the analytical column for analysis.

\subsection{Method Validation}

The developed method was validated in compliance with bioanalytical method validation guidelines published by the Ministry of Food and Drug Safety in Korea (MFDS) and the U.S. Food and Drug Administration (FDA) [23,24].

\subsubsection{Specificity and Selectivity}

To assess the selectivity of the method, six randomly selected blank human plasma samples of different origins were analyzed for the potential interference of endogenous compounds simultaneously eluted at the retention times of the analyte and the IS. No interfering peaks were observed, suggesting acceptable selectivity of the developed method.

\subsubsection{Linearity and Lower Limits of Quantification}

The calibration curve of standards was established using seven ephedrine and pseudoephedrine concentrations $(0.2,0.5,2,5,10,25$, and $50 \mathrm{ng} / \mathrm{mL})$. Linearity was evaluated by plotting the peak area ratios $(x)$ of the standard to IS versus the concentrations of the standard $(y)$ using weighted $\left(1 / x^{2}\right)$ linear least-squares regression $(y=a x+b)$ of the plasma concentrations and the measured peak area ratios. A calibration curve with a correlation coefficient $\left(r^{2}\right)$ of 0.99 or greater was deemed to have adequate linearity. The lower limit of quantification (LLOQ) was defined as the lowest concentration on the calibration curve with a signal-to-noise ratio $(\mathrm{S} / \mathrm{N})$ greater than 10 . The acceptance precision and accuracy criteria for each back-calculated standard concentration were $\pm 15 \%$ deviation from the nominal value, except at LLOQ and $\pm 20 \%$ at LLOQ.

\subsubsection{Precision and Accuracy}

Inter- and intra-day precision and accuracy were evaluated by analyzing five replicates at four different concentrations $(0.2,0.6,10$, and $50 \mathrm{ng} / \mathrm{mL})$ on three consecutive days (one run per day). The mean and standard deviation (SD) were estimated for the calculated concentrations over these batches. Accuracy and precision were presented as relative error (RE) and coefficient of variation (CV), respectively. The accuracy and precision were considered sufficient if RE and CV were within $\pm 15 \%$ for each nominal concentration except at LLOQ, where RE and CV should be within $\pm 20 \%$.

\subsubsection{Extraction Recovery and Matrix Effect}

The extraction recovery and matrix effect were evaluated by assessing the ion suppression or enhancement caused by the plasma matrix during analysis. They were analyzed based on the analytes in the pre-extraction spiked matrix ([A]), analytes in the post-extraction spiked matrix ([B]), and pure analyte solutions in $50 \%$ methanol $(v / v)([C])$. The recovery of ephedrine, pseudoephedrine, and the IS at three QC concentrations was evaluated by comparing the peak areas of [A] to the peak areas of [B], which represented $100 \%$ recovery. The matrix effect of ephedrine, pseudoephedrine, and the IS was assessed by comparing the peak areas of $[\mathrm{B}]$ with the peak areas of $[\mathrm{C}]$, and the percent ratio $(\mathrm{B} / \mathrm{C}$ $\times 100 \%$ ) was used to estimate the matrix effect.

\subsubsection{Stability}

The stability of the working solution was tested using three replicates of low-and highconcentration QC samples by comparing their peak areas with those of freshly prepared stock solutions. The working solutions were stored at room temperature for $7 \mathrm{~h}$. The stability of ephedrine and pseudoephedrine in plasma was examined under the following 
different conditions using replicates $(n=3$, at each concentration) of QC $(0.6,10$, and $40 \mathrm{ng} / \mathrm{mL}$ ): short-term stability at room temperature, $4{ }^{\circ} \mathrm{C}$, and $-70^{\circ} \mathrm{C}$ for $7 \mathrm{~h}$, freeze-thaw stability after five freeze-thaw cycles at $-70^{\circ} \mathrm{C}$, and autosampler stability at $10^{\circ} \mathrm{C}$ for $97 \mathrm{~h}$.

\subsection{Application to a Pharmacokinetic Study}

The analytical method described above was applied to analyze plasma samples obtained from a pharmacokinetic interaction study in healthy volunteers. An open-label, 1-sequence, 2-period, 2-treatment sequential crossover study was conducted in accordance with the Declaration of Helsinki and Korean Good Clinical Practice (Clinical Research Information Service, CRIS; https: / / cris.nih.go.kr (accessed on 3 November 2021) Registry Number: KCT0002447). The study was performed at the Clinical Trial Center, Kyung Hee University Hospital, Seoul, Korea. Among the 22 healthy male volunteers enrolled in this study, 20 completed the study.

OJS powder $14.47 \mathrm{~g} /$ pack was administered three times per day from the first day of OJS administration to the 7th day. On the 8th day, the last OJS was administered once. Blood samples were collected before OJS administration on the 5 th day and after $0.5 \mathrm{~h}$ of OJS administration on the 6th and 7th days. On the 8th day, blood samples were collected at $1,1.5,2,2.5,3,3.33,3.67,4,4.5,5,7,9,13,25$, and $49 \mathrm{~h}$ after the administration of the last OJS dose. The blood samples were centrifuged immediately for $10 \mathrm{~min}$, and the plasma was harvested and stored at $-70{ }^{\circ} \mathrm{C}$ until required for LC-MS/MS analysis.

Pharmacokinetic parameters were calculated using $\mathrm{R}$ version 4.1.0 (Vienna, Austria) [34] with the PKNCA version 0.9.4 library [35]. The peak plasma concentration $\left(\mathrm{C}_{\max , \mathrm{ss}}\right)$ at steady-state and the time to reach the $C_{\max , s s}\left(T_{\max }\right)$ of ephedrine and pseudoephedrine were determined using individual plasma drug concentration-time profiles on the 8th day after the first OJS administration. The area under the plasma drug concentration-time curve from the last OJS administration to the last value above the limit of quantification $\left(\mathrm{AUC}_{\text {last }}\right)$ and from the last OJS dose to $8 \mathrm{~h}$ during the dosing interval at steady-state $\left(A U C_{\tau, s s}\right)$ of ephedrine and pseudoephedrine were calculated using the linear-up logdown trapezoidal method. The terminal elimination rate constant $\left(\mathrm{k}_{\mathrm{z}}\right)$ was estimated from the regression of the log-linear decrease in the plasma concentration-time profile, and the terminal elimination half-life $\left(t_{1 / 2}\right)$ was calculated from the natural logarithm of 2 divided by $k_{z}$.

\section{Conclusions}

The newly developed LC-MS/MS method, which is simple and sufficiently sensitive, was comprehensively validated according to the MFDS and the U.S. FDA guidelines and was successfully used to simultaneously determine ephedrine and pseudoephedrine in human plasma following the oral administration of OJS powder (14.47 g/pack) with water. Given differences observed in plasma ephedrine concentrations on administering a single ephedrine extract and a multi-herbal preparation, our findings may be valuable for clarifying the pharmacokinetic characteristics of ephedrine and pseudoephedrine in OJS.

Author Contributions: Conceptualization, S.-V.Y., K.-T.L. and B.-H.K.; methodology, S.L., W.-S.S. and H.Y.; validation, W.-S.S., S.L., B.-C.L. and E.-K.C.; formal analysis, W.-S.S., and S.L.; investigation, S.L., W.-S.S., H.Y., J.Y. and S.C.; data curation, W.-S.S. and S.L.; writing-original draft preparation, W.-S.S., H.Y. and S.L.; writing-review and editing, K.-Y.L., B.-C.L., E.-K.C., K.-T.L. and B.-H.K.; supervision, K.-T.L. and B.-H.K.; project administration, K.-T.L. and B.-H.K.; funding acquisition, B.-C.L. All authors have read and agreed to the published version of the manuscript.

Funding: This study was supported by a grant from the Korea Health Technology R\&D Project through the Korea Health Industry Development Institute (KHIDI), funded by the Ministry of Health \& Welfare, Republic of Korea (grant number: HF20C0022).

Institutional Review Board Statement: The study was conducted according to the guidelines of the Declaration of Helsinki, and approved by the Institutional Review Board of Kyung Hee University Hospital (Protocol code: KHUH-K01; date of approval: 11 January 2017). 
Informed Consent Statement: Informed consent was obtained from all subjects involved in the study.

Conflicts of Interest: The authors declare no conflict of interest. The funders had no role in the design of the study; in the collection, analyses, or interpretation of data; in the writing of the manuscript, or in the decision to publish the results.

Sample Availability: Samples of the compounds are not available from authors.

\section{References}

1. Ekor, M. The growing use of herbal medicines: Issues relating to adverse reactions and challenges in monitoring safety. Front. Pharmacol. 2014, 4, 177. [CrossRef] [PubMed]

2. Woo, J.-M.; Park, E.-J.; Lee, M.; Ahn, M.; Kwon, S.; Koo, K.H. Changes in attitudes toward and patterns in traditional Korean medicine among the general population in South Korea: A comparison between 2008 and 2011. BMC Complement. Altern. Med. 2014, 14, 436. [CrossRef]

3. Lee, N.-H.; Ha, H.-K.; Lee, H.-Y.; Jung, D.-Y.; Choi, J.-Y.; Lee, J.-K.; Shin, H.-K. Analysis of studies on Ojeok-san for establishment of evidence based medicine. Herb. Formula Sci. 2008, 16, 1-9.

4. Kim, J.-H.; Lee, D.H.; Kim, J.H.; Jung, S.E.; Ham, S.H.; Yang, W.M.; Kwon, B.-I. Anti-inflammatory Effects of Ojeok-san in LPS-induced Inflammatory Rat Model. J. Korean Med. 2021, 42, 21-30. [CrossRef]

5. Yoo, S.-R.; Jeong, S.-J.; Kim, Y.-J.; Lim, H.-S.; Jin, S.-E.; Jeon, W.-Y.; Shin, I.-S.; Shin, N.-R.; Kim, S.-S.; Kim, J.-H. Effects of water and ethanol extracts from Ojeok-san on inflammation and its related diseases. J. Intern. Korean Med. 2012, 33, 418-428.

6. Ha, H.; Lee, J.K.; Lee, H.Y.; Seo, C.-S.; Kim, J.-H.; Lee, M.-Y.; Koh, W.S.; Shin, H.K. Evaluation of safety of the herbal formula Ojeok-san: Acute and sub-chronic toxicity studies in rats. J. Ethnopharmacol. 2010, 131, 410-416. [CrossRef]

7. Park, S.; Kim, Y.; Oh, M. Prescriptionology; Young Lim Press: Seoul, Korea, 2003; pp. 268-269.

8. Kim, D.; Kim, H.; Lyu, J.; Young, U.; Chan, K.; Ha, Y.; Jo, M.; Lim, J.; Hong, S. Pharmacology of Traditional Oriental Medicine; Shinilbooks: Seoul, Korea, 2005; pp. 348-353.

9. Cupp, M.J. Herbal remedies: Adverse effects and drug interactions. Am. Fam. Phys. 1999, 59, 1239.

10. Haller, C.A.; Benowitz, N.L. Adverse cardiovascular and central nervous system events associated with dietary supplements containing ephedra alkaloids. New Engl. J. Med. 2000, 343, 1833-1838. [CrossRef]

11. Skalli, S.; Zaid, A.; Soulaymani, R. Drug interactions with herbal medicines. Ther. Drug Monit. 2007, 29, 679-686. [CrossRef]

12. Wang, J.-W.; Chiang, M.-H.; Lu, C.-M.; Tsai, T.-H. Determination the active compounds of herbal preparation by UHPLC-MS/MS and its application on the preclinical pharmacokinetics of pure ephedrine, single herbal extract of Ephedra, and a multiple herbal preparation in rats. J. Chromatogr. B 2016, 1026, 152-161. [CrossRef]

13. Shao, G.; Wang, D.-S.; Wu, F.; Chen, S.-J.; Luo, X. Separation and determination of (I)-ephedrine and (d)-pseudoephedrine in plasma by high-performance liquid chromatography with fluorescence detection. J. Liq. Chromatogr. Relat. Technol. 1995, 18, 2133-2145. [CrossRef]

14. Alshana, U.; Göğer, N.G.; Ertaş, N. Ultrasound-assisted emulsification microextraction for the determination of ephedrines in human urine by capillary electrophoresis with direct injection. Comparison with dispersive liquid-liquid microextraction. J. Sep. Sci. 2012, 35, 2114-2121. [CrossRef]

15. Hou, J.; Zheng, J.; Shamsi, S.A. Simultaneous chiral separation of ephedrine alkaloids by MEKC-ESI-MS using polymeric surfactant II: Application in dietary supplements. Electrophoresis 2007, 28, 1426-1434. [CrossRef] [PubMed]

16. Jacob, P., III; Haller, C.A.; Duan, M.; Yu, L.; Peng, M.; Benowitz, N.L. Determination of ephedra alkaloid and caffeine concentrations in dietary supplements and biological fluids. J. Anal. Toxicol. 2004, 28, 152-159. [CrossRef]

17. Cooper, S.D.; Fletcher, B.L.; Rehder Silinski, M.A.; Brown, S.S.; Lodge, J.W.; Fernando, R.A.; Collins, B.J. Determination of L-ephedrine, pseudoephedrine, and caffeine in rat plasma by liquid chromatography-tandem mass spectrometry. J. Anal. Toxicol. 2011, 35, 341-348. [CrossRef] [PubMed]

18. Zhang, Q.; Chen, S.; Liu, A.; Wang, Y. Quantification of 10 bioactive components of Yazhangsan in rat plasma by LC-MS/MS and its application. Biomed. Chromatogr. 2020, 34, e4958. [CrossRef] [PubMed]

19. Maurya, A.K.; Sahu, P.L.; Jethi, S.; Gosain, H.; Sahu, K. Method Development and Validation of Ephedrine and Pseudoephedrine in Horse Urine by Liquid Chromatography-Tandem Mass Spectrometry. Indian J. Pharm. Educ. Res. 2020, 54, S671-S676. [CrossRef]

20. Beyer, J.; Peters, F.T.; Kraemer, T.; Maurer, H.H. Detection and validated quantification of nine herbal phenalkylamines and methcathinone in human blood plasma by LC-MS/MS with electrospray ionization. J. Mass Spectrom. 2007, 42, 150-160. [CrossRef] [PubMed]

21. Thevis, M.; Schänzer, W. Examples of doping control analysis by liquid chromatography-tandem mass spectrometry: Ephedrines, $\beta$-receptor blocking agents, diuretics, sympathomimetics, and cross-linked hemoglobins. J. Chromatogr. Sci. 2005, 43, 22-31. [CrossRef]

22. Zhang, J.; Zhang, Y.; Wang, Y. Validated quantification method for five ephedrines in dietary supplements using LC-MS/MS: Application to 503 cases. J. Chromatogr. B 2016, 1039, 1-7. [CrossRef] 
23. Food and Drug Administration. Bioanalytical Method Validationguidance for Industry. US Department of Health and Human Services. 2018. Available online: https:/ / www.fda.gov/media/70858/download (accessed on 3 November 2021).

24. Ministry of Food and Drug Safety. Guideline on Bioanalytical Method Validation. 2013. Available online: https://www.mfds.go. $\mathrm{kr} / \mathrm{brd} / \mathrm{m} 210 /$ down.do?brd_id=data0010\&seq=13054data_tp=A\&file_seq=1 (accessed on 3 November 2021).

25. Park, S.I.; Park, J.Y.; Park, M.J.; Yim, S.V.; Kim, B.H. Effects of Ojeok-san on the Pharmacokinetics of Celecoxib at Steady-state in Healthy Volunteers. Basic Clin. Pharmacol. Toxicol. 2018, 123, 51-57. [CrossRef]

26. Pickup, M.; May, C.; Ssendagire, R.; Paterson, J. The pharmacokinetics of ephedrine after oral dosage in asthmatics receiving acute and chronic treatment. Br. J. Clin. Pharmacol. 1976, 3, 123-134. [CrossRef]

27. Dickerson, J.; Perrier, D.; Mayersohn, M.; Bressler, R. Dose tolerance and pharmacokinetic studies of L (+) pseudoephedrine capsules in man. Eur. J. Clin. Pharmacol. 1978, 14, 253-259. [CrossRef]

28. Chan, K.H.; Pan, R.N.; Hsu, M.C. Simultaneous quantification of six ephedrines in a Mahwang preparation and in urine by high-performance liquid chromatography. Biomed. Chromatogr. 2005, 19, 337-342. [CrossRef] [PubMed]

29. Feng, H.; Luo, J.; Chen, F.; Yu, L. Human pharmacokinetics of ephedrine and pseudoephedrine in Mahuang Tang by GC-MS. Tradit. Chin. Drug Res. Clin. Pharmacol. 2000, 5.

30. Sever, P.; Dring, L.; Williams, R. The metabolism of (-)-ephedrine in man. Eur. J. Clin. Pharmacol. 1975, 9, 193-198. [CrossRef]

31. Csajka, C.; Haller, C.; Benowitz, N.; Verotta, D. Mechanistic pharmacokinetic modelling of ephedrine, norephedrine and caffeine in healthy subjects. Br. J. Clin. Pharmacol. 2005, 59, 335-345. [CrossRef] [PubMed]

32. Delbeke, F.; Debackere, M. The influence of diuretics on the excretion and metabolism of doping agents: Part VI. Pseudoephedrine. Biopharm. Drug Dispos. 1991, 12, 37-48. [CrossRef] [PubMed]

33. Chester, N.; Mottram, D.R.; Reilly, T.; Powell, M. Elimination of ephedrines in urine following multiple dosing: The consequences for athletes, in relation to doping control. Br. J. Clin. Pharmacol. 2004, 57, 62-67. [CrossRef] [PubMed]

34. Ihaka, R.; Gentleman, R. R: A language for data analysis and graphics. J. Comput. Graph. Stat. 1996, 5, $299-314$.

35. Buckeridge, C.; Duvvuri, S.; Denney, W.S. Simple, automatic noncompartmental analysis: The PKNCA R package. J. Pharmacokinet. Pharmacodyn. 2015, 42, 11-107. 